Article

\title{
Sensing Characteristics of Arrayed Flexible Chloride Sensor Based on the XBee Wireless Sensing System
}

\author{
Shi-Chang Tseng', Tong-Yu Wu ${ }^{1}$, Jung-Chuan $\mathrm{Chou}^{2,3, *}$, Yi-Hung Liao ${ }^{4}$, Chih-Hsien Lai ${ }^{2,3}$, \\ Yu-Hsun Nien ${ }^{5}$, You-Xiang $\mathbf{W u}^{3}$, Cian-Yi Wu ${ }^{3}$ and Si-Hong Lin ${ }^{3}$
}

1 Graduate School of Mechanical Engineering, National Yunlin University of Science and Technology, Douliu 64002, Taiwan, R.O.C.; E-Mail: tsengsc@yuntech.edu.tw; d10011005@yuntech.edu.tw

2 Department of Electronic Engineering, National Yunlin University of Science and Technology, Douliu 64002, Taiwan, R.O.C.; E-mail: chlai@yuntech.edu.tw

3 Graduate School of Electronic Engineering, National Yunlin University of Science and Technology, Douliu 64002, Taiwan, R.O.C.; E-mail: M10513317@yuntech.edu.tw; M10513328@yuntech.edu.tw; M10613304@yuntech.edu.tw

4 Department of Information and Electronic Commerce Management, TransWorld University, Douliu 64002, Taiwan, R.O.C.; E-mail: liaoih@mail.twu.edu.tw

5 Graduate School of Chemical and Materials Engineering, National Yunlin University of Science and Technology, Douliou, Taiwan 64002, R.O.C.; E-mail: nienyh@yuntech.edu.tw

* Correspondence: choujc@yuntech.edu.tw; Tel.: +886-534-2601 \#4333

\begin{abstract}
Water quality monitoring was an important objective in the surroundings. In this study, we investigated the sensing characteristics of the arrayed flexible chloride sensor with XBee wireless sensing system. The sensitivity and linearity of the wireless chloride sensing devices were $91.6 \mathrm{mV} / \mathrm{pCl}$ and 0.988 , respectively. The hysteresis voltages were $50.14 \mathrm{mV}$ and $36.71 \mathrm{mV}$ during the cycles of $1 \mathrm{M} \rightarrow 10^{-1} \mathrm{M} \rightarrow$ $1 \mathrm{M} \rightarrow 10^{-3} \mathrm{M} \rightarrow 1 \mathrm{M}$ and $1 \mathrm{M} \rightarrow 10^{-3} \mathrm{M} \rightarrow 1 \mathrm{M} \rightarrow 10^{-1} \mathrm{M} \rightarrow 1 \mathrm{M}$, respectively. The selectivity coefficients of the $\mathrm{ClO}^{-}$ion, $\mathrm{ClO}_{4}^{-}$ion, $\mathrm{NO}_{3}^{-}$ion and $\mathrm{I}^{-}$ion for $\mathrm{Cl}^{-}$ion were $5.0 \times 10^{-2}, 1.0 \times 10^{-1}, 5.9 \times 10^{-3}$ and $5.6 \times 10^{-1}$, respectively. The sensing characteristics of real time measurement were investigated for dynamic microfluidic. The arrayed flexible chloride sensor was integrated with the microfluidic device, syringe pump and wireless sensing system. The sensitivity and linearity were $273.1 \mathrm{mV} / \mathrm{pCl}$ and 0.978 at $35 \mu \mathrm{L} / \mathrm{min}$, respectively.
\end{abstract}

Keywords: arrayed flexible chloride sensor; wireless sensing system; hysteresis voltage; selectivity coefficient; dynamic microfluidic

\section{Introduction}

Industry countries had a common problem that was water pollutions. Water quality monitoring was an important objective in the surroundings. Many researchers [1-4] used the chemical sensors and optical sensors to measure and analyze the water compositions for the water quality. S. F. Gonski et al. [1] used the Honeywell Durafet $\mathrm{pH}$ sensor to measure the $\mathrm{pH}$ variations of the river. They investigated the water pollution levels by Honeywell Durafet $\mathrm{pH}$ sensor. N. Kato et al. [2] investigated the residual chlorine concentrations of the tap water by detecting electrode and compensating electrode.

They investigated the residual chlorine selectivity for their sensors, thus the interferences obtained the hydrogen ion concentration $(\mathrm{pH})$ and dissolved oxygen (DO). A. Aisopou et al. [3] used electrochemical and optical technologies to measure conductivity, $\mathrm{pH}$, free chlorine, total chlorine, DO, oxidative redox potential (ORP) and turbidity. N. Carbó et al. [4] used the voltammetry electronic tongue and pulse voltammetry method to investigate the quality parameters in spring water. The composition of the spring water contained nitrate, sulfate, fluoride, chloride, sodium. The $\mathrm{pH}$ ranges of spring water were from 7.3 to 7.8 .

The drawbacks of the water quality monitoring were the detection distance limit and operation space limit. Many researchers detected different ions and obtained experiment data easier with wireless sensing system [5-15]. The wireless sensing system had been applied to different fields, such as chloride ion detection [5-16], hydrogen ion detection [17-23], glucose detection [23-25] and lactate detection [25].

S. Zhuiykov et al. [5] investigated the wireless sensing devices of the conductivity, $\mathrm{pH}$, dissolved metal ions, dissolved oxygen (DO) and dissolved organic carbon (DOC). K. G. Ong et al. [6] detected accurately the hypochlorite ion variations with the wireless sensing devices. The hypochlorite ions sensor integrated with 
wireless transmission system, and investigated the hypochlorite ion concentration variations, and the hypochlorite ion sensor included the layer of polyurethane and alumina on the magnetically-soft ferromagnetic ribbon. S. Zhou et al. [7] used the $\mathrm{Ag} / \mathrm{AgCl}$ electrode, reference electrode and radio-frequency identification (RFID) communication protocol to measure and investigate the chloride ion concentrations in the concrete.

N. Harris et al. [8] used the screen printed technology to prepare the low cost robust chloride ion sensor. They investigated the sensing characteristic of the chloride ion sensor with IEEE 802. 15. 4 and secure digital (SD) memory card. The chloride sensors were applied to measure the chloride ion concentration for soil column, fluvarium and greenhouse. K. A. Nyni et al. [9] developed the wireless health monitoring system for health monitoring, which contained the devices of the electro cardio gram (ECG), electroencephalogram (EEG) and electromyogram (EMG). They used the Arduino UNO board and Bluetooth module to construct the wireless transmission. J. F. Cheng et al. [10] fabricated the chloride ion sensing devices and Bluetooth wireless measurement system. The wireless sensing devices were used to measure response voltage from $10^{-4}$ to $1 \mathrm{M} \mathrm{NaCl}$ solutions.

Our research group [11] investigated the sensing characteristic of the $\mathrm{RuO}_{2}$ chloride ion sensing devices with voltage-time (V-T) measurement system and wireless remote control platform. Our research group [12] integrated the current-voltage (I-V) measurement system with the three Keithley 236 semiconductor parameter analyzers. They investigated the sensing characteristic of the wireless chloride sensor. V. A. T. Dam et al. [13] prepared sweat sensing device by screen printing system. They integrated the sweat sensing device with high impedance voltmeter (Keithley 617A). They investigated the hysteresis effects and detected chloride ion concentrations of the sweat. K. Smettem et al. [14] prepared the wireless chloride ion sensing devices by the screen printed technology, central microcontroller (MCU), real-time clocks (RTC), GPS module and IEEE 802. 15. 4 standard. Their wireless chloride ion sensing devices applied to monitor the water quality of the stream. Y. Abbas et al. [15] investigated the sensing characteristic of near-field-inductive coupling (NFC) of sensing devices and readout coils with the $\mathrm{Ag} / \mathrm{AgCl}$ electrode. The capacitance variation were from 180 to $200 \mathrm{pF}$ when the chloride ion concentrations from 0.01 to $0.2 \mathrm{M}$, respectively. J. Jung et al. [16] used the three-electrode electrochemical amperometric analyzer to investigate the sensing characteristics from $1 \mathrm{mM}$ to $100 \mathrm{mM}$ of ruthenium (III) chloride (Ru III). The three electrodes, current-to-voltage (I/V) measurement, Bluetooth 4.0 module (WT-12, Bluegiga, Espoo, Finland) and notebook computer were used to set up the three-electrode electrochemical amperometric analyzer. They repaired the silver (Ag) counter electrode and silver-silver chloride $(\mathrm{Ag} / \mathrm{AgCl})$ reference and indium tin oxide (ITO) working electrode on the ITO glass.

R. Yue et al. [17] integrated solar power supply with wireless sensor system. The wireless sensors were used to detect $\mathrm{pH}$, turbidity and oxygen density. W. Dang et al. [18] used the graphite-polyurethane composite to prepare the $\mathrm{pH}$ sensor. The sensitivity of the RFID wireless $\mathrm{pH}$ sensor was $11.13 \mathrm{mV} / \mathrm{pH}$. The wireless $\mathrm{pH}$ sensor was used to detect sweat $\mathrm{pH}$ variation. L. Lu et al. [19] investigated the human gastrointestinal (GI) physiological information by wireless capsule. They repaired the $\mathrm{pH}$ micro sensor, pressure micro sensor, temperature micro sensor and radio frequency (RF) transceiver in the wireless capsule. The wireless capsule was used to real test for the animal (pig) and three healthy volunteers. They obtained more data for $\mathrm{pH}$, temperature and pressure by the wireless capsule.

R. Rahimi et al. [20] prepared the transparent $\mathrm{pH}$ sensor and near field communication (NFC) wireless measurements for wound infection monitoring. The NFC wireless transparent $\mathrm{pH}$ sensor was investigated the hysteresis effect, drift effect from $\mathrm{pH} 4$ to $\mathrm{pH} 10$. R. A. Croce et al. [21] used the winding $125 \mu \mathrm{m}$ platinum $(\mathrm{Pt})$ and silver wire to fabricate the coil-type electrochemical $\mathrm{pH}$ sensing devices. They used the coil-type $\mathrm{pH}$ sensing devices, $\mathrm{Ag} / \mathrm{AgCl}$ reference electrode, saturated calomel electrode (SCE), Bluetooth transceiver and computer to investigate the $\mathrm{pH}$ detection. B. Zhou et al. [22] repaired the optical fiber sensor to measure the $\mathrm{pH}$ solutions. The $\mathrm{pH}$ experiment data was transferred to computer by Zigbee wireless network.

Our research group studied the wireless sensing system of XBee module with sensing devices [23-25]. The wireless sensing system was used to investigate the sensitivities for many kinds of the chemical substances, such as pH [23], glucose [23-25] and lactate [25]. The advantages of the wireless sensing system of XBee module were high stability, lost cost, portable device, easy operation, rapid detection and real-time monitor [23]. P. Abouzar et al. [26] used the Zigbee wireless system and measurement to investigate the sensing characteristics of wireless sensor networks for precision agriculture. N. A. Cloete et al. [27] integrated the flow sensing device, temperature sensing device, conductivity sensing device, $\mathrm{pH}$ sensing device with the 
106

107

108

109

110

111

\section{2}

113

114

115

116

117

118

119

120

121

122

123

124

125

126

127

128

129

130

XBee wireless module. They used the XBee wireless water quality monitoring system to investigate the sensing characteristic for real time water quality detection.

In order to develop the real-time monitor of chloride ion detection, therefore wireless sensing measurement of XBee integrated with the arrayed flexible $\mathrm{RuO}_{2} / \mathrm{GO}$ chloride ion sensor to investigate the selectivity coefficients, hysteresis effect, and dynamic microfluidic measurement of the arrayed flexible $\mathrm{RuO}_{2} / \mathrm{GO}$ chloride ion sensor.

\section{Materials and Methods}

\subsection{Materials}

The polyethylene terephthalate (PET) was purchased from Zencatec Corporation (Taiwan). PET sheet was flexible and light weight, which was the substrate of the chloride sensing device. Ruthenium target (Ru, 99.95 wt $\%$ ) was purchased from Ultimate Materials Technology Co., Ltd. (Taiwan), which was used to deposit the membrane of ruthenium dioxide $\left(\mathrm{RuO}_{2}\right)$ by the radio frequency (R. F.) sputtering system.

The silver paste and epoxy thermosetting polymer (product no. JA643) were purchased from Advanced Electronic Material Inc. (Taiwan) and Everwide Chemical Co., Ltd. (Taiwan), respectively. The applications of the silver paste and epoxy thermosetting polymer were conductive wire and insulation layer, respectively.

The poly(vinyl chloride) (PVC), bis (2-ethylhexyl) sebacate (DOS) solution (95\%), chloride ionophore III (ETH9033) and tridodecylmethy-lammonium chloride (TDDMACl) were purchased from Sigma-Alorich Co., Ltd. (USA). The tetrahydrofuran (THF) solution were purchased from Nan Ya Plastics Co., Ltd. (Taiwan). THF solution, PVC powder, DOS solution, ETH9033 powder and TDDMACl powder were used to prepare the chloride ion mixture. The sodium cloride $(\mathrm{NaCl})$ was purchased from Avantor Performance Materials, Inc. (USA), it was used to prepare the diffferent chloride ion concentrations from $10^{-5} \mathrm{M}$ to $1 \mathrm{M} \mathrm{NaCl}$ solutions.

XBee router and XBee coordinator were purchased from Digi International Inc. (USA). XBee router, XBee coordinator and Arduino Mega 2560 microcontroller board were used to transfer the experiment data to computer.

\subsection{Fabrication of the arrayed flexible $\mathrm{RuO}_{2} / G O$ chloride ion sensor}

The producing process of the flexible arrayed $\mathrm{RuO}_{2} / \mathrm{GO}$ chloride sensor was shown in Figure 1 . The preparation method of the flexible arrayed $\mathrm{RuO}_{2} / \mathrm{GO}$ chloride sensor was followed the Refs. [28-31]. Then, we dropped $2 \mu \mathrm{L}$ of the chloride ion mixture on the sensing windows of the $\mathrm{GO} / \mathrm{RuO}_{2}$ sensing devices, respectively. The $\mathrm{GO} / \mathrm{RuO}_{2}$ chloride ion sensors were dried at room temperature $\left(25{ }^{\circ} \mathrm{C}\right)$ during 4 days.

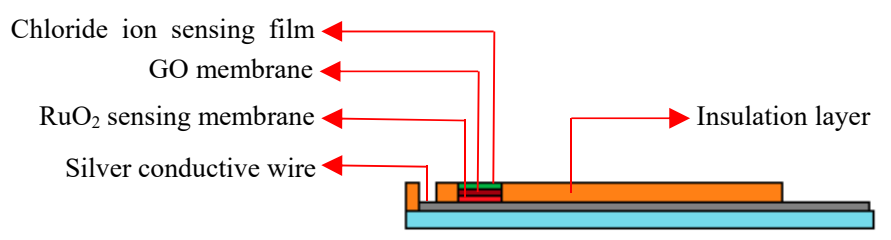

(a)

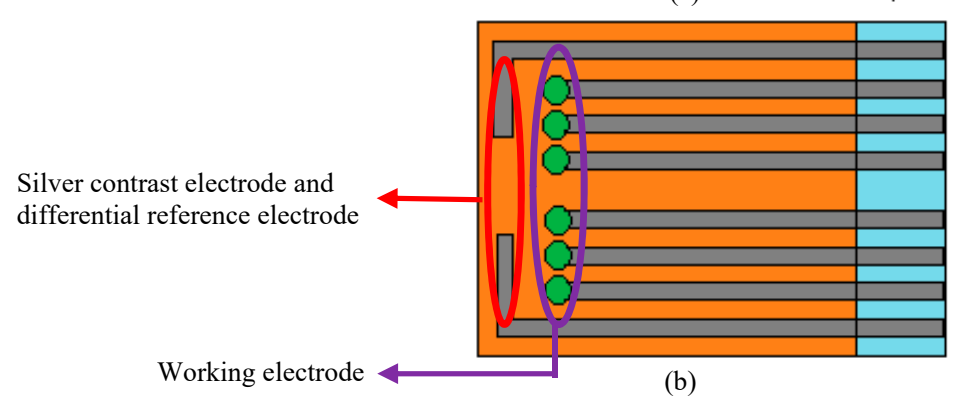

Figure 1. The producing process of the flexible arrayed $\mathrm{RuO}_{2} / \mathrm{GO}$ chloride sensor [28-31]. (a) The diagrammatic sketch of the different sensing structures for the flexible arrayed $\mathrm{RuO}_{2} / \mathrm{GO}$ chloride sensor (b) The schematic diagram of the silver contrast electrode, differential reference electrode and working electrode. 


\subsection{Wireless sensing system}

The schematic diagram of wireless sensing system of XBee module was shown in Figure 2. The real picture of the wireless sensing system of XBee module was shown in Figure 3 [23-25]. The wireless sensing system of the XBee module contained computer, XBee coordinator, power supply, wireless sensing measurement and flexible arrayed $\mathrm{RuO}_{2} / \mathrm{GO}$ chloride ion sensor, the wireless sensing measurement of the contained 6-channel readout circuit device, XBee router, Arduino Mega 2560 and analysis software (model: LabVIEW 2012). The six instrumentation amplifiers (AD623) were used to construct the 6-channel readout circuit device. We used the wireless sensing system to measure response voltages with different chloride ion concentrations from $10^{-5}$ $\mathrm{M}$ to $1 \mathrm{M} \mathrm{NaCl}$ solutions. The sensitivity, selectivity coefficients and hysteresis voltage were investigated by the wireless sensing system. From Figure 4, the wireless sensing system, microfluidic device and syringe pump were used to measure response voltage and investigate real-time monitor of chloride ion detection with different flow rates from $5 \mu \mathrm{L} / \mathrm{min}$ to $40 \mu \mathrm{L} / \mathrm{min}$.

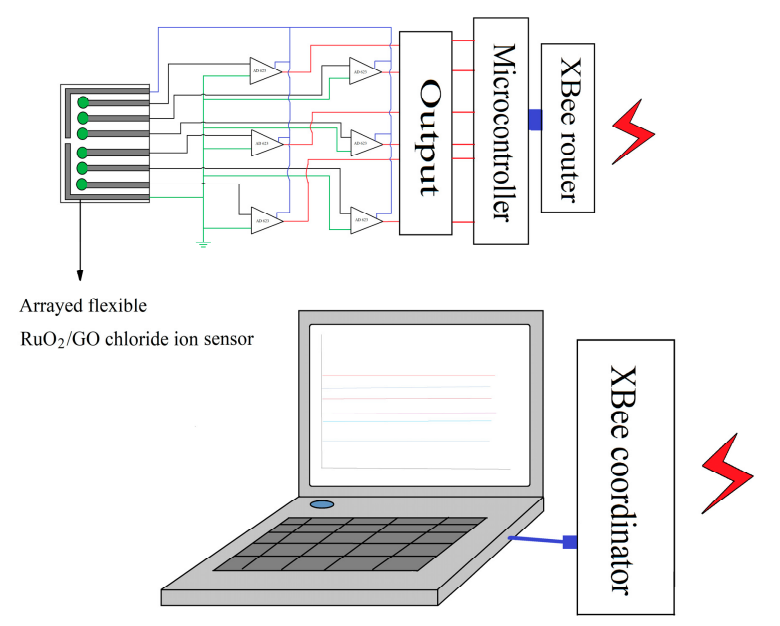

Figure 2. The schematic diagram of wireless sensing system with the flexible arrayed $\mathrm{RuO}_{2} / \mathrm{GO}$ chloride ion sensor [23-25].

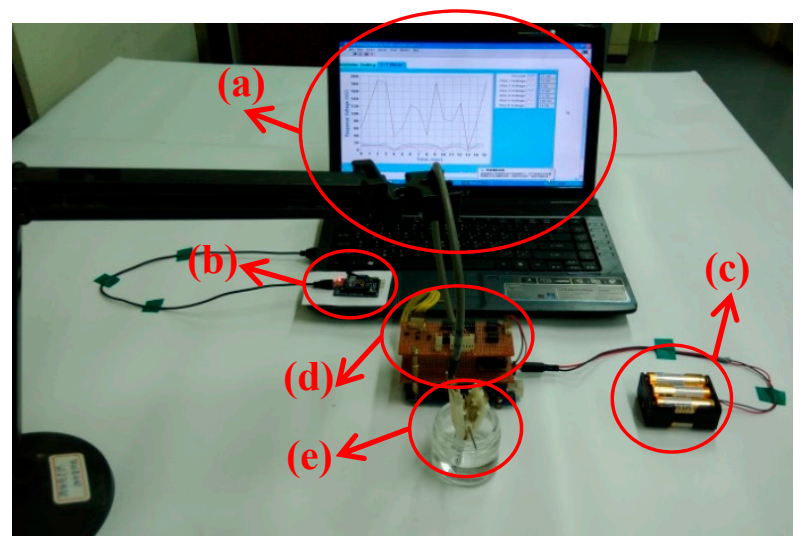

Figure 3. The wireless sensing system with the flexible arrayed $\mathrm{RuO}_{2} / \mathrm{GO}$ chloride ion sensor. (a) Computer, (b) $\mathrm{XBee}$ coordinator, (c) power supply (d) wireless sensing measurement (XBee router) and (e) flexible arrayed $\mathrm{RuO}_{2} / \mathrm{GO}$ chloride ion sensor [23-25]. 
168

169

170

171

172

173

174

175

176

177

178

179

180

181

182

183

184

185

186

\section{7}

188

189

190

191

192

193

194

195

196

197

198

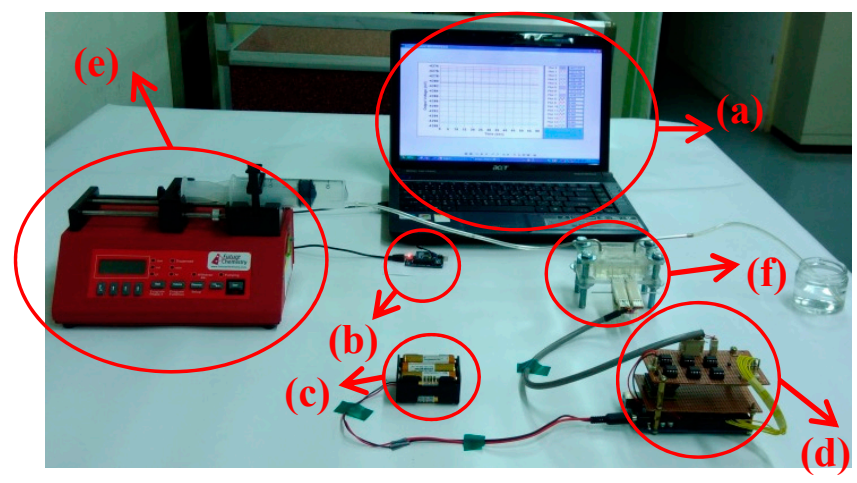

Figure 4. The wireless sensing system with microfluid dymanic system. (a) computer, (b) XBee coordinator, (c) power supply (d) wireless sensing measurement (XBee router), (e) syringe pump and (f) microfluidic device [23-25].

\section{Results and Discussion}

\subsection{Sensitivity in the static state}

We investigated the sensitivity and linearity of chloride ion sensing device with wireless sensing system. From Figure 5, the sensitivity and linearity were $91.6 \mathrm{mV} / \mathrm{pCl}$ and 0.988 , respectively. We used the instrumentation amplifiers (AD623) with 2 times gain and set the parameters in LabVIEW, which amplified the voltage value of the flexible arrayed $\mathrm{RuO}_{2} / \mathrm{GO}$ chloride ion sensor. The sensitivity comparisons of the chloride ion sensing devices were shown in Table 1. The wireless transmission technology was obtained the RFID [7], Bluetooth [10]. S. Zhou et al. [7] prepare the wireless chloride ion sensor. The sensitivity of wireless chloride ion sensor was $47.83 \mathrm{mV} / \mathrm{pCl}$.

Our group used the voltage-time measurement system and the chloride ion devices to measure response voltages and obtained the sensitivity of chloride ion devices [28-30]. The voltage-time measurement system (V-T measurement system) was not wireless data transmission. Therefore, the detection distance of the chloride ion sensing device with voltage-time measurement system was shorter than chloride ion sensing device with wireless sensing system.

\subsection{Sensitivity in the dynamic microfluid}

The sensitivity variations of the arrayed flexible chloride sensor were integrated by the microfluidic device, syringe pump and wireless sensing system. From Figure 6, the sensitivities of the wireless chloride ion sensor were increased when the flow rates increasing from $5 \mu \mathrm{L} / \mathrm{min}$ to $40 \mu \mathrm{L} / \mathrm{min}$. The boundary layer was produced by friction and viscous force, and the boundary layer was between chloride membrane and molecular electrolyte [28-30]. The boundary layer thickness was decreased when flow rate increasing. Therefore, the sensitivities of the wireless chloride ion sensor were increased when the flow rates increasing. The best average sensitivity and linearity were $273.1 \mathrm{mV} / \mathrm{pCl}$ and 0.978 at $35 \mu \mathrm{L} / \mathrm{min}$, respectively. When the flow rate was over $35 \mu \mathrm{L} / \mathrm{min}$, the sensitivities were decreased. The flexible arrayed $\mathrm{RuO}_{2} / \mathrm{GO}$ chloride ion sensor with the wireless sensing system was quick response and convenient operation, which could be applied to monitor chloride ion concentrations in real time. 
199

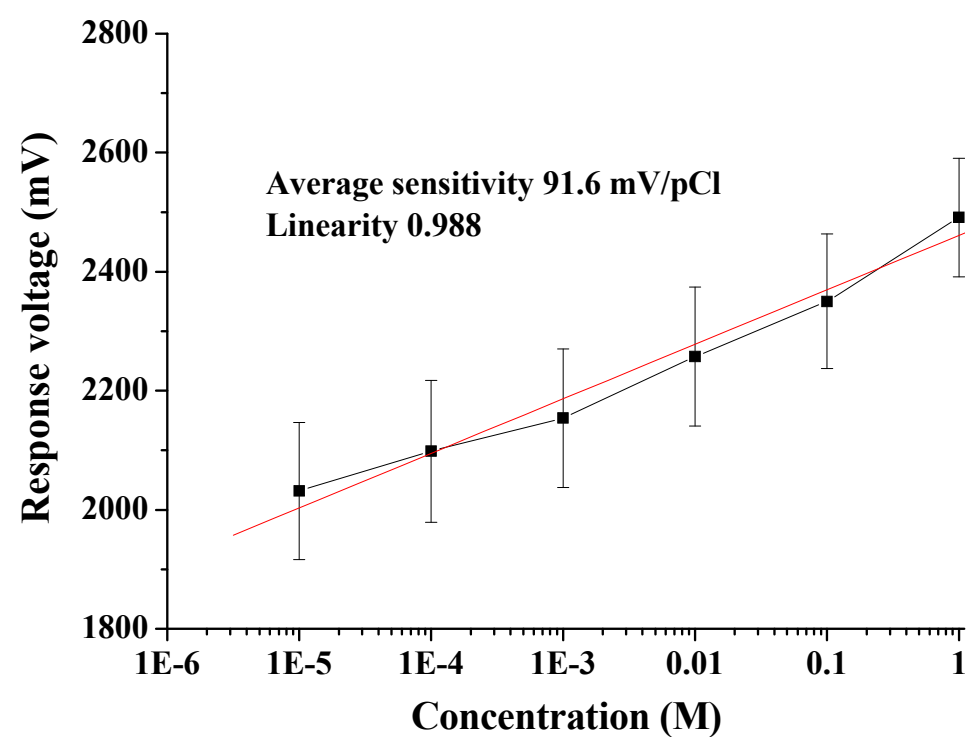

Figure 5. The curve of the response voltage versus concentration for the flexible arrayed $\mathrm{RuO}_{2} / \mathrm{GO}$ chloride ion sensor integrated in the wireless sensing system between $10^{-5} \mathrm{M}$ and $1 \mathrm{M} \mathrm{NaCl}$ solutions.

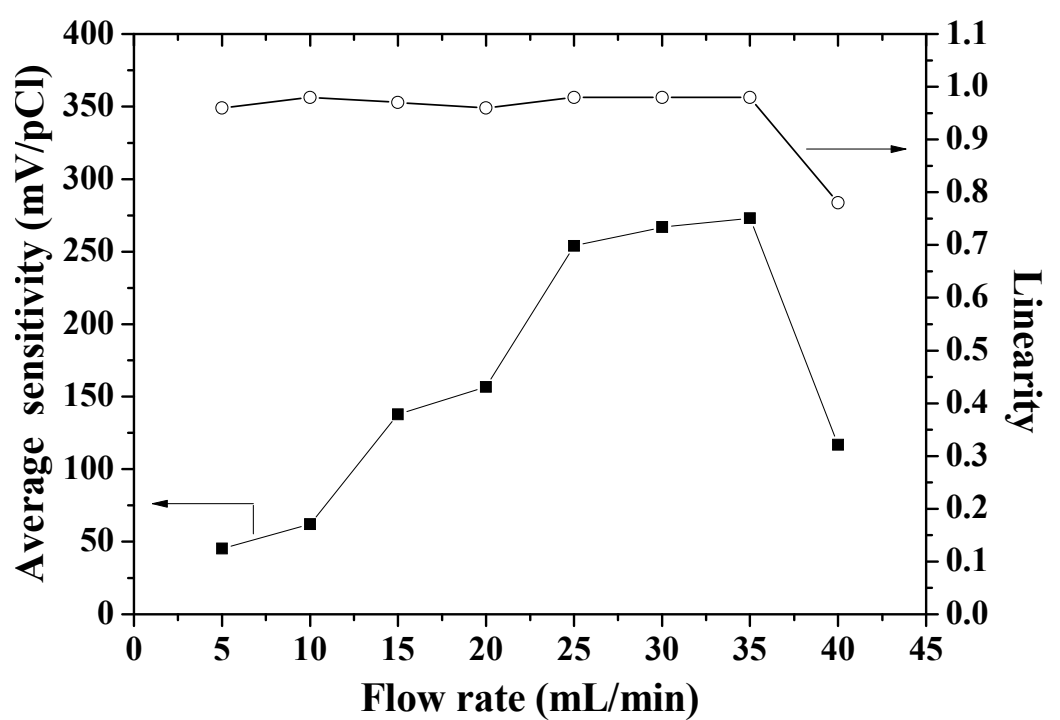

Figure 6. The average sensitivity and linearity of the flexible arrayed $\mathrm{RuO}_{2} / \mathrm{GO}$ chloride ion sensor with the wireless sensing system at different flow rates from $5 \mu \mathrm{L} / \mathrm{min}$ to $40 \mu \mathrm{L} / \mathrm{min}$. 
Table 1. The comparisons of the chloride ion sensing devices with other literatures in different chloride ion

\begin{tabular}{|c|c|c|c|c|}
\hline Sensing electrode & Measurement system & $\begin{array}{l}\text { Test solutons } \\
\text { (M) }\end{array}$ & $\begin{array}{l}\text { Average } \\
\text { sensitivity } \\
(\mathrm{mV} / \mathrm{pCl})\end{array}$ & Ref. \\
\hline $\begin{array}{c}\mathrm{RuO}_{2} / 0.01 \mathrm{wt} \% \mathrm{GO} / \text { Chloride ion } \\
\text { selective membrane }\end{array}$ & XBee wireless V-T sensing system & $\begin{array}{c}10^{-5} \text { to } 1 \\
\mathrm{NaCl} \text { solutions }\end{array}$ & 91.6 & $\begin{array}{l}\text { In this } \\
\text { study }\end{array}$ \\
\hline $\begin{array}{l}\mathrm{Ag} / \mathrm{AgCl} \text { electrode and reference } \\
\text { electrode }\end{array}$ & RFID communication protocol & $\begin{array}{c}10^{-4} \text { to } 1 \\
\mathrm{NaCl} \text { solutions }\end{array}$ & 47.8 & $\begin{array}{c}{[7]} \\
2017 \\
\end{array}$ \\
\hline $\begin{array}{l}\text { ITO glass } / \mathrm{SnO}_{2} / \text { Chloride ion } \\
\text { selective membrane }\end{array}$ & $\begin{array}{c}\text { Bluetooth wireless measurement } \\
\text { system }\end{array}$ & $\begin{array}{c}10^{-4} \text { to } 1 \\
\mathrm{NaCl} \text { solutions }\end{array}$ & 51.4 & $\begin{array}{r}{[10]} \\
2012 \\
\end{array}$ \\
\hline $\begin{array}{l}\text { Silicon substrate/ } \mathrm{RuO}_{2} / \text { chlorine ion } \\
\text { selective membrane }\end{array}$ & $\begin{array}{c}\text { Voltage-time (V-T) measurement } \\
\text { system and wireless remote control } \\
\text { platform }\end{array}$ & $\begin{array}{c}0 \text { to } 1.34 \times 10^{-4} \\
\mathrm{NaClO} \\
\text { solutions } \\
\end{array}$ & $1.8 \mathrm{mV} / \mathrm{ppm}$ & $\begin{array}{r}{[11]} \\
2012\end{array}$ \\
\hline $\begin{array}{c}\text { Silicon wafer } / \mathrm{RuO}_{2} / \text { chlorine ion } \\
\text { selective membrane }\end{array}$ & $\begin{array}{c}\text { Current-voltage (I-V) measurement } \\
\text { system } \\
\text { with three Keithley } 236 \\
\text { semiconductor parameter analyzers }\end{array}$ & $\begin{array}{l}10^{-4} \text { to } 1 \\
\mathrm{NaCl} \text { solutions }\end{array}$ & 59.0 & $\begin{array}{l}{[12]} \\
2012\end{array}$ \\
\hline $\begin{array}{c}\text { Polyethylene terephthalate /dupont } \\
5876 \mathrm{AgCl} \text { conducting paste/ dupont } \\
8153 \text { insulating paste/ pHEMA } \\
\text { hydrogel layer }\end{array}$ & $\begin{array}{l}\text { High impedance voltmeter } \\
\text { (Keithley 617A) }\end{array}$ & $\begin{array}{c}10^{-3} \text { to } 3 \\
\mathrm{NaCl} \text { solutions }\end{array}$ & 58.0 & $\begin{array}{l}{[13]} \\
2016\end{array}$ \\
\hline $\begin{array}{l}\text { Polyethylene terephthalate } \\
/ \mathrm{RuO}_{2} / \text { Chloride ion selective } \\
\text { membrane }\end{array}$ & V-T measurement system & $\begin{array}{c}10^{-5} \text { to } 1 \\
\mathrm{NaCl} \text { solutions }\end{array}$ & 25.1 & $\begin{array}{l}{[28]} \\
2016\end{array}$ \\
\hline $\begin{array}{c}\text { Polyethylene terephthalate } \\
/ \mathrm{RuO}_{2} / 0.01 \mathrm{wt} \% \mathrm{GO} / \text { Chloride ion } \\
\text { selective membrane }\end{array}$ & V-T measurement system & $\begin{array}{l}10^{-5} \text { to } 1 \\
\mathrm{NaCl} \text { solutions }\end{array}$ & 44.5 & $\begin{array}{l}{[29]} \\
2018\end{array}$ \\
\hline $\begin{array}{l}\text { Polyethylene terephthalate } \\
/ \mathrm{RuO}_{2} / \text { Chloride ion selective } \\
\text { membrane }\end{array}$ & V-T measurement system & $\begin{array}{l}10^{-4} \text { to } 1 \\
\mathrm{NaCl} \text { solutions }\end{array}$ & 26.2 & $\begin{array}{l}{[31]} \\
2012\end{array}$ \\
\hline
\end{tabular}

\subsection{Investigation of the hysteresis voltage}

The response voltages of the flexible arrayed $\mathrm{RuO}_{2} / \mathrm{GO}$ sensors were measured by the V-T measuring system with different measurement cycles of chloride ion concentrations, which from $10^{-3} \mathrm{M}$ to $1 \mathrm{M} \mathrm{NaCl}$ solutions by XBee wireless modules. The experimential results were shown in Figure 7 and Figure 8 . The hysteresis voltages were $50.14 \mathrm{mV}$ and $36.71 \mathrm{mV}$ during the cycles of $1 \mathrm{M} \rightarrow 10^{-1} \mathrm{M} \rightarrow 1 \mathrm{M} \rightarrow 10^{-3} \mathrm{M} \rightarrow 1$ $\mathrm{M}$ and $1 \mathrm{M} \rightarrow 10^{-3} \mathrm{M} \rightarrow 1 \mathrm{M} \rightarrow 10^{-1} \mathrm{M} \rightarrow 1 \mathrm{M}$, respectively.

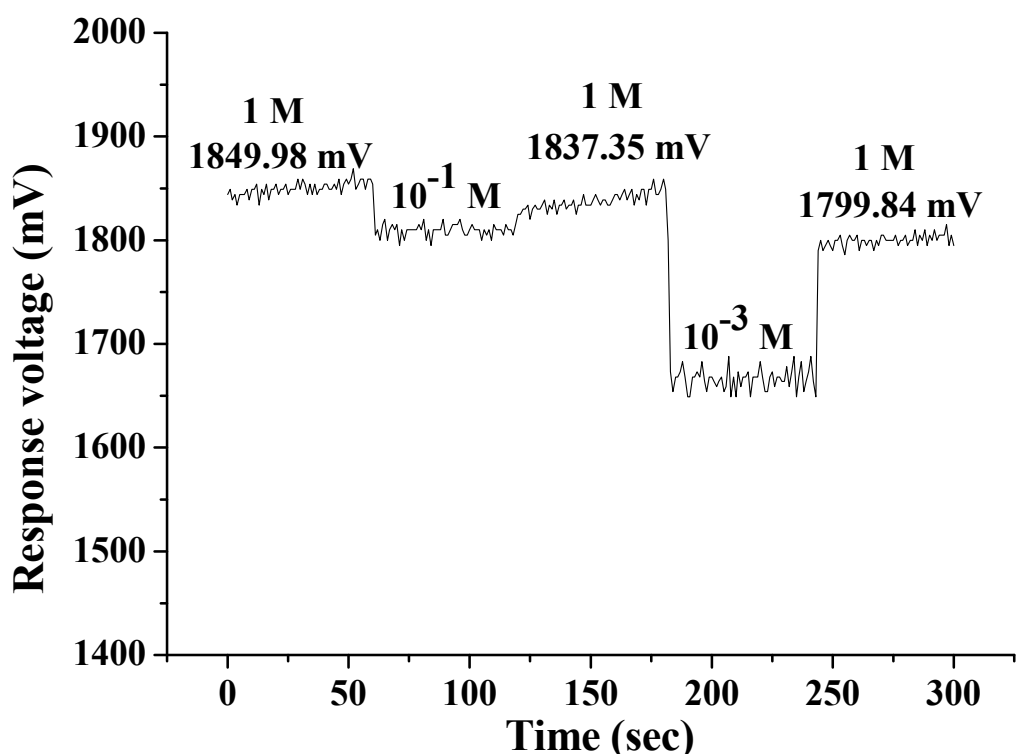

Figure 7. The response voltages of the flexible arrayed $\mathrm{RuO}_{2} / \mathrm{GO}$ chloride ion sensor in the $\mathrm{NaCl}$ solutions during the cycle of $1 \mathrm{M} \rightarrow 10^{-1} \mathrm{M} \rightarrow 1 \mathrm{M} \rightarrow 10^{-3} \mathrm{M} \rightarrow 1 \mathrm{M}$. 


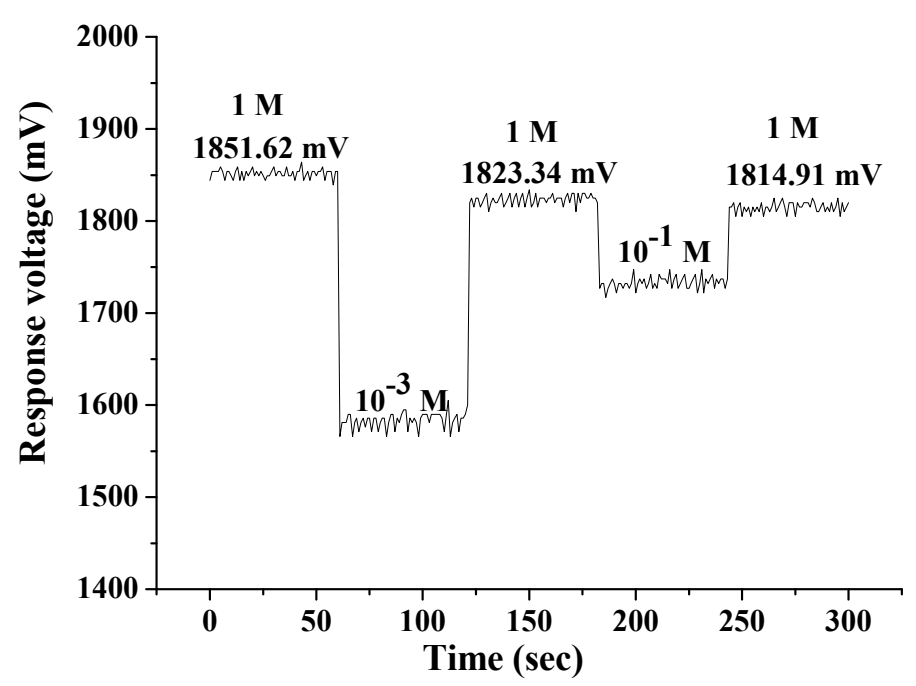

Figure 8. The response voltages of the flexible arrayed $\mathrm{RuO}_{2} / \mathrm{GO}$ chloride ion sensor in the $\mathrm{NaCl}$ solutions during the cycle of $1 \mathrm{M} \rightarrow 10^{-3} \mathrm{M} \rightarrow 1 \mathrm{M} \rightarrow 10^{-1} \mathrm{M} \rightarrow 1 \mathrm{M}$.

\subsection{Investigation of the selectivity coefficients}

In this study, we checked the chloride ion selectivity of chloride ion sensing devices with wireless sensing system. We prepared the $30 \mathrm{~mL}$ different chloride concentrations from $10^{-5} \mathrm{M}$ to $1 \mathrm{M} \mathrm{NaCl}$ solutions as the major ion $\mathrm{A}$, respectively. The other interfering ions $\mathrm{B}$ contained $10^{-3} \mathrm{M} \mathrm{ClO}^{-}$solution, $10^{-3} \mathrm{M} \mathrm{ClO}_{4}^{-}$solution, $10^{-3} \mathrm{M} \mathrm{NO}_{3}^{-}$solution and $10^{-3} \mathrm{M} \mathrm{I}^{-}$solution. The $10^{-5} \mathrm{M}$ to $1 \mathrm{M} \mathrm{NaCl}$ solutions were based on a fixed major ion concentration. The selectivity coefficient was obtained from Equations (1) and (2):

$$
\begin{gathered}
\Delta a_{A}=a_{A}^{\prime}-a_{A} \\
\mathrm{~K}_{A, B}^{p o t}=\frac{\Delta a_{A}}{a_{B}}
\end{gathered}
$$

Where $\Delta a_{A}$ was the increasing quantity of the major ion; $a_{A}^{\prime}$ was the equal concentration when the interfering ion reaches its maximum value; $a_{A}$ was the concentration of the background solution; $a_{B}$ was the maximum concentration of the interfering ion; and $\mathrm{K}_{A, B}^{\text {pot }}$ was the selectivity coefficient of matched potential method (MPM) [32]. J. F. Cheng et al. [33] calculated the $K_{c l^{-} / j}^{\text {pot }}$ values of the $\mathrm{HPO}_{4}{ }^{2-}, \mathrm{F}^{-}, \mathrm{SO}_{4}{ }^{-}$, $\mathrm{Br}^{-}, \mathrm{I}^{-}$ions for chloride ion selectivity by MPM. They found the $K_{C l^{-} / j}^{p o t}$ value sequences were $\mathrm{I}^{-}>\mathrm{Br}^{-}>$ $\mathrm{SO}_{4}^{-}>\mathrm{F}^{-}>\left(\mathrm{HPO}_{4}^{2-}\right)$. K. G. Kumar et al. [34] investigated the $K_{C l^{-} / j}^{\text {pot }}$ values of the $\mathrm{Zn}^{2+}, \mathrm{Fe}^{3+}, \mathrm{Cu}^{2+}, \mathrm{Na}^{+}$, $\mathrm{Mn}^{2+}, \mathrm{Co}^{2+}, \mathrm{K}^{+}, \mathrm{Ca}^{2+}, \mathrm{NO}_{3}{ }^{-}, \mathrm{Br}^{-}, \mathrm{NO}_{2}^{-}, \mathrm{CH}_{3} \mathrm{COO}^{-}$and $\mathrm{SO}_{4}{ }^{2-}$ ions for chloride ion selectivity. We used the MPM to investigate the chloride selectivity coefficients in this study. From Table 2, the selectivity coefficients of the $\mathrm{ClO}^{-}$ion, $\mathrm{ClO}_{4}^{-}$ion, $\mathrm{NO}_{3}^{-}$ion and $\mathrm{I}^{-}$ion with $\mathrm{Cl}^{-}$ion were $5.0 \times 10^{-2}, 1.0 \times 10^{-1}, 5.9 \times 10^{-3}$ and $5.6 \times 10^{-1}$, respectively. We found the $\mathrm{K}_{\mathrm{Cl}^{-} / \mathrm{j}}^{\mathrm{pot}}$ value sequences were $\mathrm{I}^{-}>\mathrm{ClO}_{4}^{-}>\mathrm{ClO}^{-}>\mathrm{NO}_{3}^{-}$. According to the experimental results, the chloride ion sensor with the wireless sensing system had good chloride ion selectivity. 
272

273

Table 2. The selectivity coefficients of the chloride ion sensor with the wireless sensing system under four different interfering ions.

\begin{tabular}{cc}
\hline Interfering ions & Selectivity coefficients log $\mathrm{K}_{\mathrm{Cl}^{-} / \mathbf{j}}^{\mathrm{pot}}$ \\
\hline $\mathrm{ClO}^{-}$ & $5.0 \times 10^{-2}$ \\
$\mathrm{ClO}_{4}^{-}$ & $1.0 \times 10^{-1}$ \\
$\mathrm{NO}_{3}^{-}$ & $5.9 \times 10^{-3}$ \\
$\mathrm{I}^{-}$ & $5.6 \times 10^{-1}$ \\
\hline
\end{tabular}

\subsection{Chloride ion detection of the tap water}

Water chlorination of the water treatment plant was an important process for drinking water. The sterilization capabilities were from free chlorine. The free chlorine were contained the hypochlorous acid $(\mathrm{HClO})$ and hypochlorite ion $\left(\mathrm{ClO}^{-}\right)$concentrations $[7,34]$. We used the wireless sensing system to investigate the sensitivity and linearity for different $\mathrm{NaClO}$ solutions from $10^{-6} \mathrm{M}$ to $1 \mathrm{M}$. From Figure 9 , the average sensitivity and linearity were $28.92 \mathrm{mV} / \mathrm{pCl}$ and 0.982 , respectively, and it could be found the flexible arrayed $\mathrm{RuO}_{2} / \mathrm{GO}$ chloride ion sensor integrated in wireless sensing system had good stability for chloride ion concentration. From Figure 10, the average response voltage was $1978.34 \pm 9.89 \mathrm{mV}$ in tap water with XBee wireless measurement system. The chloride concentration ranges of the tap water was between were between $10^{-5} \mathrm{M}$ and $10^{-4} \mathrm{M}$.

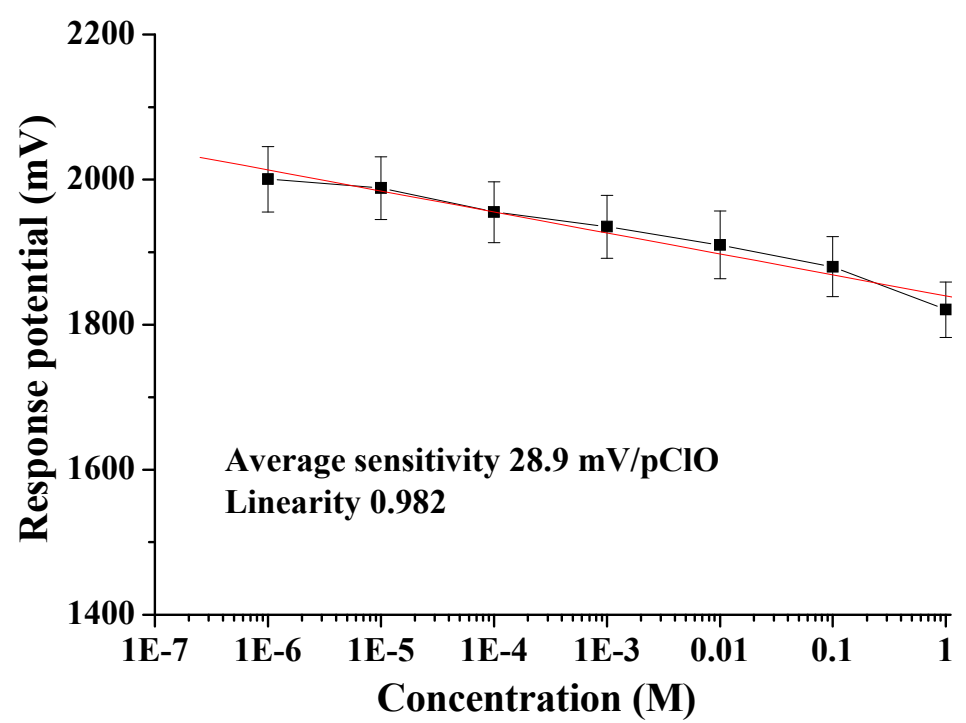

Figure 9. The curve of the response voltages versus concentration for the flexible arrayed $\mathrm{RuO}_{2} / \mathrm{GO}$ chloridne ion sensor with the wireless sensing system in the $10^{-6} \mathrm{M}$ and $1 \mathrm{M} \mathrm{NaClO}$ solutions. 


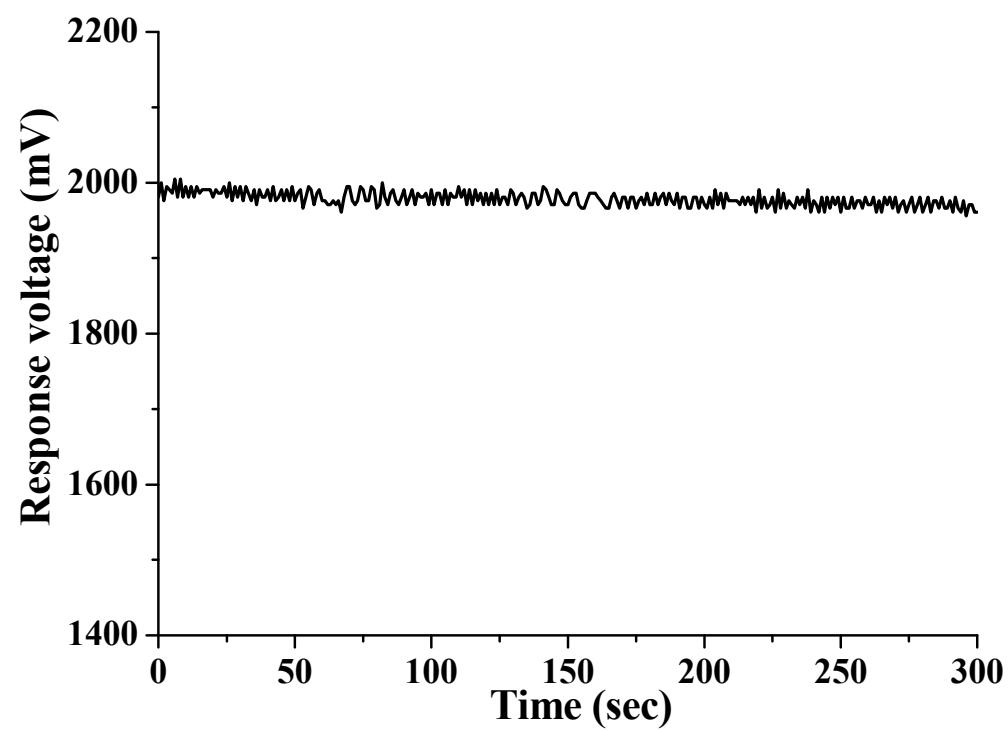

Figure 10. The response voltage curve of flexible arrayed $\mathrm{RuO}_{2} / \mathrm{GO}$ chloride ion sensor with the wireless sensing system in the tap water.

\section{Conclusions}

The sensitivity and linearity of the chloride ion sensor with the wireless sensing system were $91.6 \mathrm{mV} / \mathrm{pCl}$ and 0.988 , respectively. The sensitivity and linearity of the flexible arrayed $\mathrm{RuO}_{2} / \mathrm{GO}$ chloride ion sensor with the XBee wireless sensing system and dynamic microfluidic were $273.1 \mathrm{mV} / \mathrm{pCl}$ and 0.978 at $35 \mu \mathrm{L} / \mathrm{min}$, respectively. The hysteresis voltages were $50.14 \mathrm{mV}$ and $36.71 \mathrm{mV}$ during the cycles of $1 \mathrm{M} \rightarrow 10^{-1} \mathrm{M} \rightarrow 1$ $\mathrm{M} \rightarrow 10^{-3} \mathrm{M} \rightarrow 1 \mathrm{M}$ and $1 \mathrm{M} \rightarrow 10^{-3} \mathrm{M} \rightarrow 1 \mathrm{M} \rightarrow 10^{-1} \mathrm{M} \rightarrow 1 \mathrm{M}$, respectively. The selectivity coefficients of the $\mathrm{ClO}^{-}$ion, $\mathrm{ClO}_{4}^{-}$ion, $\mathrm{NO}_{3}^{-}$ion and $\mathrm{I}^{-}$ion with $\mathrm{Cl}^{-}$ion were $5.0 \times 10^{-2}, 1.0 \times 10^{-1}, 5.9 \times 10^{-3}$ and $5.6 \times 10^{-1}$, respectively. The above experimental results had proved that the wireless sensing system with the flexible arrayed $\mathrm{RuO}_{2} / \mathrm{GO}$ chloride ion sensor had good selectivity and good stability for chloride ion detection. contracts MOST 106-2221-E-224-023 and MOST 106-2221-E-224-047.

Author Contributions: Shi-Chang Tseng, Jung-Chuan Chou and Tong-Yu Wu conceived and designed the experiments; Tong-Yu Wu and Si-Hong Lin performed the experiments; Cian-Yi Wu and Yi-Hung Liao analyzed the data; You-Xiang $\mathrm{Wu}$ and Chih-Hsien Lai checked the analyzed data; Yu-Hsun Nien and Jung-Chuan Chou contributed reagents/materials/analysis tools; Tong-Yu Wu wrote the paper; Jung-Chuan Chou revised the paper.

Conflicts of Interest: The authors declare no conflict of interest.

\section{References}

314 1. Gonski, S. F; Cai, W. J.; Ullman, W. J.; Joesoef, A.; Main, C. R.; Pettay, D. T.; Martz, T. R. Assessment of the suitability of durafet-based sensors for $\mathrm{pH}$ measurement in dynamic estuarine environments. Estuar. Coast. Mar. Sci., 2018, 200, 152-168.

2. Kato, N.; Hirano, N.; Okazaki, S.; Matsushita, S.; Gomei, T. Development of an all-solid-state residual chlorine sensor for tap water quality monitoring. Sens. Actuators, B, 2017, 248, 1037-1044.

3. Aisopou, A.; Stoianov, I.; Graham, N. J. D. In-pipe water quality monitoring in water supply systems under steady and unsteady state flow conditions: a quantitative assessment. Water Res., 2012, 46, 235-246.

4. Carbó, N.; Carrero, J. L.; Castillo, F. J. G.; Tormos, I.; Olivas, E.; Folch, E.; Fillol, M. A.; Soto, J. Quantitative determination of spring water quality parameters via electronic tongue, Sensors, 2018, 18, 1-12.

5. Zhuiykov, S. Solid-state sensors monitoring parameters of water quality for the next generation of wireless sensor networks, Sens. Actuators, B, 2012, 161, 1-20. 
6. Ong, K. G.; Paulose, M.; Grimes, C. A. A wireless, passive, magnetically-soft harmonic sensor for monitoring sodium hypochlorite concentrations in water, Sensors, 2003, 3, 11-18.

7. Zhou, S.; Sheng, W.; Deng, F.; Wu, X.; Fu, Z. A novel passive wireless sensing method for concrete chloride ion concentration monitoring, Sensors, 2017, 17, pp. 1-13.

8. Harris, N.; Cranny, A.; Rivers, M.; Smettem, K.; Lennard, E. G. B. Application of distributed wireless chloride sensors to environmental monitoring: initial results, IEEE Trans Instrum Meas, 2016, 65, 736-743.

9. Nyni, K. A.; Vincent, L. K; Varghese, L.; Liya, V. L.; Johny, A. N.; Yesudas, C. V. Wireless health monitoring system for ECG, EMG and EEG detecting, 2017 International Conference on Innovations in Information, Embedded and Communication Systems (ICIIECS), Coimbatore, India, Mar. 2017, 5 pages.

10. Cheng, J. F.; Chou, J. C.; Sun, T. P.; Hsiung, S. K.; Kao, H. L. Study on a multi-ions sensing system for monitoring of blood electrolytes with wireless home-care system, IEEE Sens. J., 2012, 12, 967-977.

11. Chou, J. C.; Su, M. W.; Chen, C. C.; Yang, S. Y. Cl ${ }^{-}$and $\mathrm{H}^{+}$sensing devices for water quality monitoring system,” Circuits and Systems (ISCAS), 2012 IEEE International Symposium on, South Korea, May 2012, 4 pages.

12. Chou, J. C.; Chen, C. C.; Lee, C. C. Development of microcontroller applied to chlorine ion measurement system, IEEE Sens. J., 2012, 12, 2215-2221.

13. Dam, V. A. T.; Zevenbergen, M. A. G.; Schaijk, R.van Toward wearable patch for sweat analysis, Sens. Actuators, $B$, 2016, 236, 834-838.

14. Smettem, K.; Klaus, J.; Harris, N.; Pfister, L. New potentiometric wireless chloride sensors provide high resolution information on chemical transport processes in streams, Water, 2017, 9, 1-16.

15. Abbas, Y.; Have, B. T.; Hoekstra, G. I.; Douma, A.; Bruijn, D. D.; Olthuis, W.; Berg, A. V. D. Connecting to concrete: wireless monitoring of chloride ions in concrete structures, Procedia Engineering, 2015, 120, 965-968.

16. Jung, J.; Lee, J.; Shin, S.; Kim, Y. T. Development of a telemetric, miniaturized electrochemical amperometric analyzer, Sensors, 2017, 17, 1-9.

17. Yue, R.; Ying, T. A novel water quality monitoring system based on solar power supply \& wireless sensor network, Procedia Environmental Sciences, 2012, 12, 265-272.

18. Dang, W.; Manjakkal, L.; Navaraj, W. T.; Lorenzelli, L.; Vinciguerra, V.; Dahiya, R. Stretchable wireless system for sweat pH monitoring, Biosens Bioelectron, 2018, 107, 1092-202.

19. Lu, L.; Yan, G.; Zhao, K.; Xu, F. An implantable telemetry platform system with asic for in vivo monitoring of gastrointestinal physiological information, IEEE Sens. J., 2015, 15, 3524-3534.

20. Rahimi, R.; Brener, U.; Chittiboyina, S.; Soleimani, T.; Detwiler, D. A.; Lelièvre, S. A.; Ziaie, B. Laser-enabled fabrication of flexible and transparent $\mathrm{pH}$ sensor with near-field communication for in-situ monitoring of wound infection, Sens. Actuators, B, 2018, 267, 198-207.

21. Croce, R. A.; Vaddiraju, S.; Legassey, A.; Zhu, K.; Islam, S. K.; Papadimitrakopoulos, F.; Jain, F. C. A highly miniaturized low-power cmos-based pH monitoring platform, IEEE Sens. J., 2015, 15, 895-901.

22. Zhou, B.; Yang, S.; Sun, T.; Grattan, K. T. V. A novel wireless mobile platform to locate and gather data from optical fiber sensorsintegrated into a WSN, IEEE Sens. J., 2015, 15, 3615 -3621.

23. Chou, J. C.; Chen, J. T.; Liao, Y. H.; Lai, C. H.; Chen, R. T.; Tsai, Y. L.; Lin, C. Y.; Chen, J. S.; Huang, M. S.; Chou, H. T. Wireless sensing system for flexible arrayed potentiometric sensor based on XBee module, IEEE Sens. J., 2016, 16, 5588-5595.

24. Chou, J. C.; Chen, R. T.; Liao, Y. H.; Chen, J. S.; Huang, M. S.; Chou, H. T. Dynamic and wireless sensing measurements of potentiometric glucose biosensor based on graphene and magnetic beads, IEEE Sens. J., 2015, 15, 5718-5725.

25. Chou, J. C.; Yan, S. J.; Liao, Y. I.; Lai, C. H.; Wu, Y. X.; Wu, C. Y. Remote detection for glucose and lactate based on flexible sensor array, IEEE Sens. J., 2018, 18, 3467-3474.

26. Cloete, N. A.; Malekian, R.; Nair, L. Design of smart sensors for real-time water quality monitoring, IEEE Access, 2016, 4, 3975-3990.

27. Abouzar, P.; Michelson, D. G.; Hamdi, M. RSSI-based distributed self-localization for wireless sensor networks used in precision agriculture, IEEE Trans. Wireless Commun., 2016, 15, 6638-6650.

28. Tseng, S. C.; Wu, T. Y.; Chou, J. C.; Liao, Y. H.; Lai, C. H.; Chen, J. S.; Huang, M. S. Research of non-ideal effect and dynamic measurement of the flexible arrayed chlorine ion sensor, IEEE Sens. J., 2016, 16, 4683-4690.

29. Tseng, S. C.; Wu, T. Y.; Chou, J. C.; Liao, Y. H.; Lai, C. H.; Chen, J. S.; Yan, S. J.; Huang, M. S.; Tseng, T. W.; Nien, Y. H. Research of sensing characteristic and dynamic measurement of graphene oxides modified flexible arrayed $\mathrm{RuO}_{2}$ chlorine ion sensor, Mater. Res. Bull., 2018, 101, 155-161. 
378

379

380

381

382

383

384

385

386

387

388
30. Chou, J. C.; Ye, G. C.; Wu, D. G.; Chen, C. C. Fabrication of the array chlorine ion sensor based on microfluidic device framework, Solid-State Electron., 2012, 77, 87-92.

31. Tseng, S. C.; Wu, T. Y.; Chou, J. C.; Liao, Y. H.; Lai, J. S.; Yan, S. J.; Tseng, T. W. Investigation of sensitivities and drift effects of the arrayed flexible chloride sensor based on $\mathrm{RuO}_{2} / \mathrm{GO}$ at different temperatures, Sensors, 2018, 18, 632-1- 632-12.

32. Cheng, J. F.; Chou, J. C.; Sun, T. P.; Hsiung, S. K.; Kao, H. L. Study on all-solid-state chloride sensor based on tin oxide/indium tin oxide glass, Jpn. J. Appl. Phys., 2011, 50, 037001-1 - 037001-8.

33. Kumar, K. G.; John, K. S.; Indira, C. J. A chloride ion-selective potentiometric sensor based on a polymeric schiff base complex, Indian J. Chem. Technol., 2006, 13, 13-16.

34. Helbling, D. E.; Briesen, J. M. V. Continuous monitoring of residual chlorine concentrations in response to controlled microbial intrusions in a laboratory-scale distribution system, Water Res., 2008, 42, 3162-3172. 